\title{
Hypertension in SHR after Abdominal Sympathectomy
}

\author{
Juro Irivahijima and Yoshinobu Numao
}

In acute experiment under pentobarbital anesthesia, bilateral splanchnicectomy reduces the blood pressure of SHR and control rats to the same level. This is a finding as if the hypertension of SHR were maintained by a hyperactivity of the sympathetic vasoconstrictors innervating the splanchnic area. However, when the SHR was kept alive after this operation, the hypertension returned in a few days. Even removal of the whole abdominal sympathetic chain with the splanchnic nerve could not impede the relapse of hypertension.

Therefore, except in a few days after the operation, it was usually impossible to differentiate sympathectomized SHR from intact SHR by mere pressure measurement. However, when the rats were anesthetized with pentobarbital or diuretics were administered to them, blood pressure was lowered more markedly in sympathectomized SHR than in intact or shamoperated SHR.

SHR was anesthetized with thiamylal sodium ( $50 \mathrm{mg} / \mathrm{Kg}$, i.p.). After laparotomy by a median incision along the linea alba, the abdominal sympathetic chain was removed bilaterally from the level of the diaphragm to that of the renal vessels with the splanchnic nerve. This operation will be referred to as "abdominal sympathectomy" hereafter. Effects of pentobarbital and diuretics were studied after the rats had recovered from this operation.

Before pentobarbital anesthesia, the mean tail blood pressure measured with a cuff and strain gauge was $181 \pm 18.2$ (SD) $\mathrm{mmHg}, \mathrm{n}=6$, for SHR $4.5 \pm$ 2.2 days after abdominal sympathectomy. It was reduced to $91.2 \pm 5.85 \mathrm{mmHg}$ $(-46.1 \pm 7.19 \%)$ when the rats were fully anesthetized 5-10 min after intraperitoneal injection of pentobarbital sodium at a dose of $30-50 \mathrm{mg} / \mathrm{Kg}$. For intact SHR the mean tail blood pressure was $178 \pm 17.4 \mathrm{mmHg}, \mathrm{n}=8$, before anesthesia and $146 \pm 18.2 \mathrm{mmHg}(-18.0 \pm 9.63 \%)$ after anesthesia. The percent decrease was significantly larger in the sympathectomized group $(\mathrm{P}<0.001)$.

The effect of pentobarbital was also studied by direct measurement of blood pressure. Twenty min after intraperitoneal injection of pentobarbital sodium $(30-50 \mathrm{mg} / \mathrm{Kg})$, the mean arterial pressure measured by cannulating the femoral artery was $104 \pm 20.7 \mathrm{mmHg}, \mathrm{n}=12$, for SHR $34.6 \pm 15.2$ days 
after abdominal sympathectomy and $142 \pm 27.2 \mathrm{mmHg}, \mathrm{n}=5$, for intact $\mathrm{SHR}$. The difference was significant at $\mathbf{P}<0.025$. The tail blood pressure measured before anesthesia had not been significantly different between the groups. After further administration of hexamethonium bromide $(30 \mathrm{mg} / \mathrm{Kg}$, i.v.) in the anesthetized state, the mean arterial pressure decreased to $62.5 \pm 8.95$ $\mathrm{mmHg}$ for the abdominal-sysmpathectomized SHR and to $66.4 \pm 10.1 \mathrm{mmHg}$ for the intact SHR. The difference was no longer significant after ganglion blockage.

Intraperitoneal injection of a diuretic, hydroflumethiazide $(25 \mathrm{mg} / \mathrm{Kg})$, lowered the tail blood pressure of abdominal-sympathectomized SHR $(9.3 \pm$ 5.5 days after sympathectomy) from $181 \pm 32.0 \mathrm{mmHg}$ to $146 \pm 25.0 \mathrm{mmHg}$ $(-18.2 \pm 11.3 \%), \mathrm{n}=10$, in 6 hours. For intact or sham-operated SHR, the mean tail blood pressure was reduced from $185 \pm 17.3 \mathrm{mmHg}$ to $177 \pm 21.4$ $\mathrm{mmHg}(-4.71 \pm 5.31 \%), \mathrm{n}=7$. The percent decrease was significantly greater in the former $(\mathrm{P}<0.01)$.

Peroral administration of hydrochlorothiazide (about $17 \mathrm{mg} / \mathrm{Kg} /$ day) lowered the tail blood pressure of SHR, about 2 weeks after abdominal sympathectomy, from $200 \pm 21.6 \mathrm{mmHg}$ to $149 \pm 6.46 \mathrm{mmHg}, \mathrm{n}=5, \quad(\mathrm{P}<0.005)$ in 4 days. The same administration induced no significant change in tail blood pressure in intact SHR, though body weight was decreased similarly in both groups.

An interpretation of the above findings will be as follows: Both pentobarbital and diuretics tend to decrease blood pressure. The former is a depressant on the heart and, presumably, also on the smooth muscle of resistance and capacitance vessels. The latter is expected to decrease plasma volume, cardiac output and vascular smooth muscle tone. The decrease in blood pressure by either drug is detected by arterial baroreceptors and, when the abdominal sympathetics are intact, are compensated for by a reflex excitation of sympathetic vasoconstrictors to splanchnic resistance and capacitance vessels. Therefore, the decrease in blood pressure was observed only after abdominal sympathectomy.

(Supported by grants from the Ministry of Education, the Japan Heart Foundation, Inc, and the Central Research Laboratory of Sankyo Co.)

(Supported by grants from the Ministry of Education, the Japan Heart Foundation, Inc, and the Central Research Laboratory of Sankyo Co.) 